\title{
Visuospatial Deficit and Apraxia in Posterior Cortical Atrophy (PCA): a Single Case Follow-up Study
}

Lucio D'Anna*, Pier Luigi Dolso, Simone Lorenzut, Anna Perelli, Barbara Zanchettin, Mariarosaria Valente and Gian Luigi Gigli

Centre for Neurodegenerative Disorders, Neurology Clinic, University of Udine Medical School, Udine, Italy

"Corresponding author: Lucio D'Anna, Centre for Neurodegenerative Disorders, Neurology Clinic, University of Udine Medical School, Udine, Italy, Tel: 393492530016; E-mail: luciodanna@hotmail.it

Rec date: May 06, 2014, Acc date: Jun 05, 2014, Pub date: Jun 08, 2014

Copyright: (C) 2014 D'Anna L, et al. This is an open-access article distributed under the terms of the Creative Commons Attribution License, which permits unrestricted use, distribution, and reproduction in any medium, provided the original author and source are credited.

\begin{abstract}
Posterior cortical atrophy (PCA) is a rare neurodegenerative syndrome characterized by insidious onset and selective, gradual decline in visuospatial and visuoperceptual skills.

We report a typical case of a patient with posterior cortical atrophy who presented initially with visuospatial deficit and apraxia. The aim of this report is to present this rare dementia subtype as a relevant differential diagnosis in respect to other neurodegenerative syndromes.
\end{abstract}

\section{Introduction}

Posterior cortical atrophy (PCA) is a rare neurodegenerative syndrome characterized by insidious onset and selective, gradual decline in visuospatial and visuoperceptual skills. Benson et al. in 1988 [1] for the first time described this rare but disabling dementia syndrome, in which visuo-spatial and visuo-perceptual impairments are the main clinical manifestations, often associated with alexia, prosopagnosia, environmental disorientation, features of Balint's syndrome and Gerstmann's syndrome [2]. Memory and verbal fluency are relatively well-preserved. Age at onset is typically before 65 years old [3].

Alzheimer's disease (AD) seems to be the most common underlying cause of PCA, however it has been described in associations with Huntingtons' disease, Lewy body dementia, Creutzfeldt-Jakob disease, cortico-basal degeneration and subcortical gliosis [4].

We report a typical case of a patient with PCA who presented initially with visuospatial deficit and apraxia. The aim of this report is to present this rare dementia subtype as a relevant differential diagnosis in respect to other neurodegenerative syndromes.

\section{Case Summary}

A 60-year-old right-handed woman was admitted to the Centre for Neurodegenerative Disorders, University of Udine, Italy, presenting progressive dyspraxic difficulties, deficits in writing and visuoperceptual problems since the last eight months.

At the age of 40 years, she was diagnosed as affected by breast tumour and underwent surgical intervention, followed by chemotherapy. Since the age of 45 has been treated for hypothyroidism.

Her family history was negative for any neurodegenerative condition, psychiatric disease or substance abuse. Her parents died at the age of 76 and 69 years, respectively, without cognitive deficits and his 77 -year-old sister was still living and in good health.
The patient, who completed only the fifth grade of the elementary school, retired at the age of 58 years from her occupation as an industrial worker. Two years later, her husband reported the onset of mood deflection. In the last eight months she has progressively lost her ability to draw and write and developed problems with dressing, washing, using cutlery and handlings tools.

At admission, the neurological examination revealed signs of left visual neglect, optic ataxia and ocular apraxia. No alien limb phenomenon was documented. She scored 24/30 at Mini-Mental State Examination (MMSE).

Neuropsychological testing revealed severe ideomotor and ideational apraxia and visuospatial problems. The copy of a simple figure was impossible. Writing was impaired. Executive functions were compromised and a clear neglect was evident. Memory and fluent speech was intact, with a clear difficulty in naming tasks (Table 1).

Laboratory tests were within normal range. Structural neuroimaging demonstrated bilateral cortical atrophy, mainly located in the occipital and parietal lobes (Figure 1). Brain structural changes were confirmed by Single Photon Emission Computerized Tomography (99mTc SPECT), and extensive hypoperfusion in the parieto-occipito-temporal regions, mainly affecting the right hemisphere, was documented (Figure 2). Cerebrospinal (CSF) analysis was consistent with $\mathrm{AD}$ pattern, with decreased $\mathrm{Ab} 42(426 \mathrm{pg} / \mathrm{mL}$, cutoff $>500 \mathrm{pg} / \mathrm{mL})$ and increased Tau $(607 \mathrm{pg} / \mathrm{mL}$, cut-off $<350$ $\mathrm{pg} / \mathrm{mL})$ and phospho-Tau $(71 \mathrm{pg} / \mathrm{mL}$, cut-off $<60 \mathrm{pg} / \mathrm{mL}$, as suggested by manufacturer, Kit-ELISA: Innotest Phospho-Tau) levels. Electroencephalography showed theta waves on posterior regions, bilaterally. In agreement with current clinical criteria, a diagnosis of PCA was made [5,6]. Namely, it was defined as biparietal variant according to the Alladi et al. classification [7]. The patient started therapy with transdermal rivastigmine $(4.6 \mathrm{mg} / 24 \mathrm{~h})$. At one-year follow-up, the neuropsychological examination showed that visuospatial praxis, writing and executive functions were significantly worsened. Language and verbal memory, largely preserved in the previous examination, were also significantly worsened (Table 1 and 
Citation: D'Anna L, Dolso PL, Lorenzut S, Perelli A, Zanchettin B, et al. (2014) Visuospatial Deficit and Apraxia in Posterior Cortical Atrophy (PCA): a Single Case Follow-up Study. J Neurol Disord 2: 166. doi:10.4172/2329-6895.1000166

Page 2 of 5

Figure 3A-3C). The patient had become totally dependent in her daily living activities.

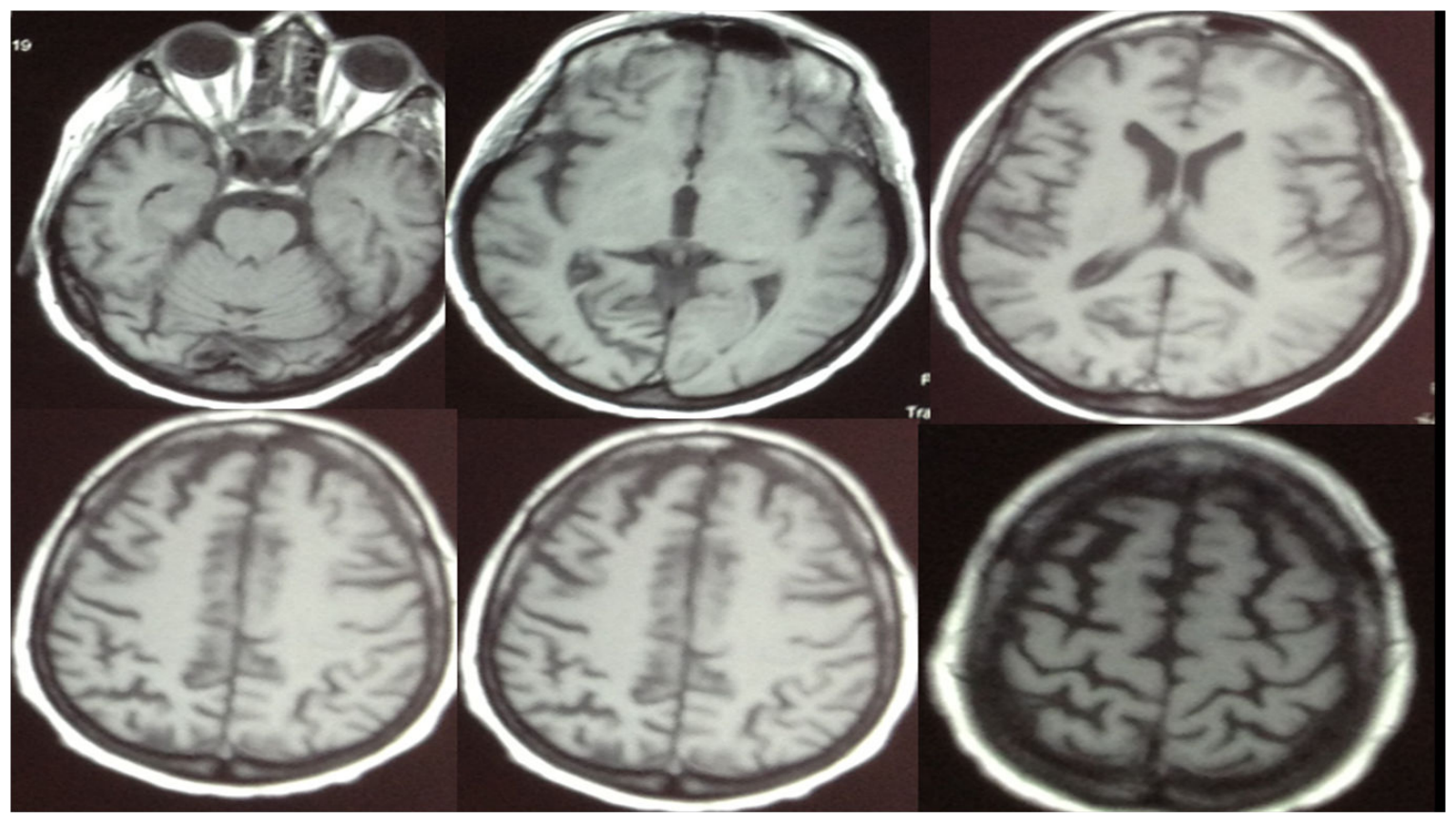

Figure 1: MRI scan performed at admission.

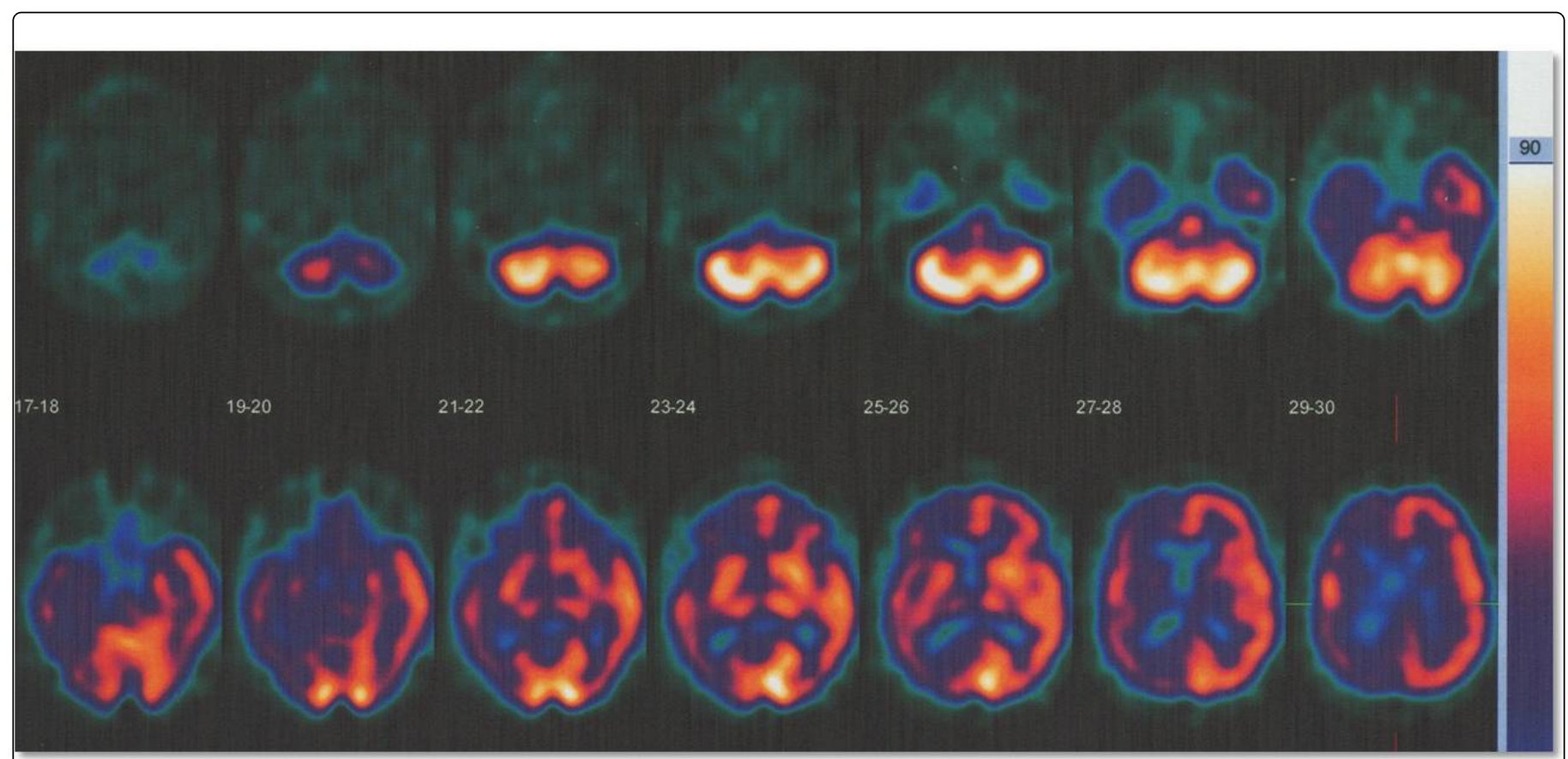

Figure 2: Single Photon Emission Computerized Tomography (99mTc SPECT) study at admission. 
Citation: D'Anna L, Dolso PL, Lorenzut S, Perelli A, Zanchettin B, et al. (2014) Visuospatial Deficit and Apraxia in Posterior Cortical Atrophy (PCA): a Single Case Follow-up Study. J Neurol Disord 2: 166. doi:10.4172/2329-6895.1000166

Page 3 of 5

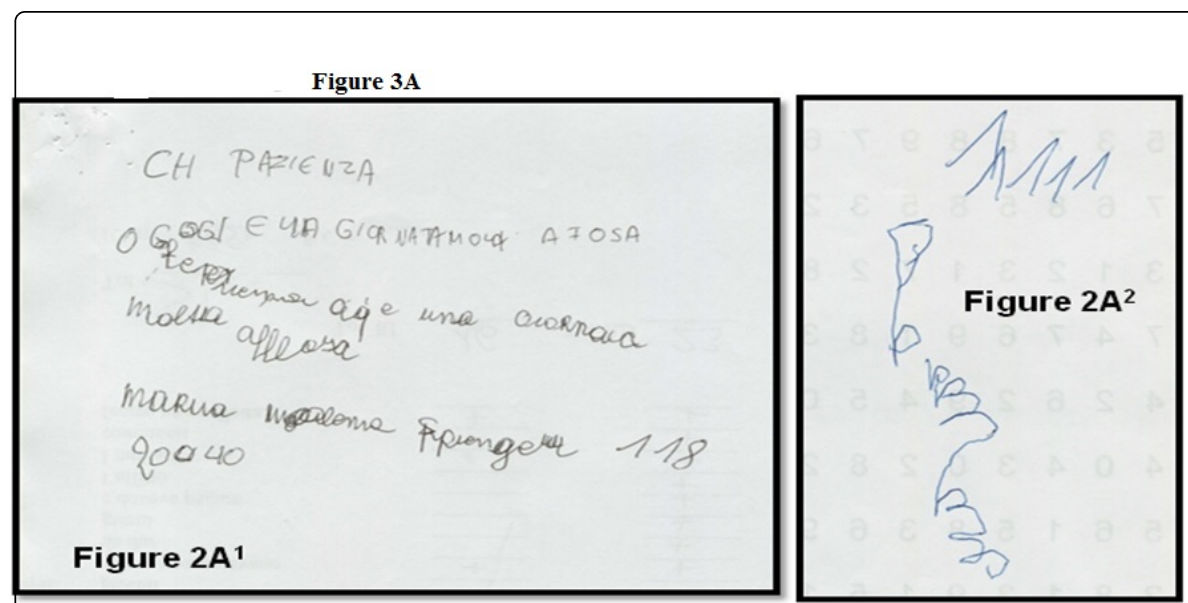

Figure 3C

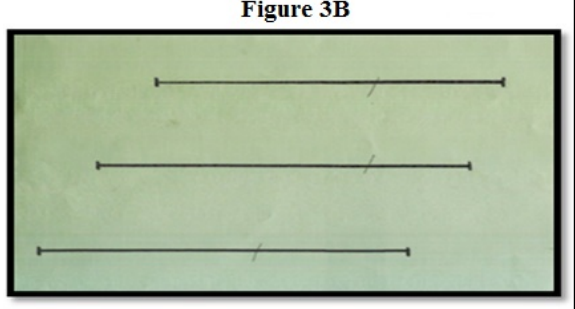

Figure 2C1

Figure 2C2

Figure 3: Neuropsychological study. Figure 3A: Writing test performed at admission (Figure 2A1) and one year later (Figure 2A2); Figure 3B: Visually neglect test performed at admission; Figure 3C: Shape Copy test performed at admission (Figure 2C1) and one year later (Figure 2C2).

\begin{tabular}{|c|c|c|c|c|}
\hline $\begin{array}{l}\text { Cognitive Domains } \\
\text { and Test }\end{array}$ & $\begin{array}{l}\text { (Correct Score) } \\
\text { Baseline } \\
\text { evaluation }\end{array}$ & $\begin{array}{l}\text { (Correct Score) } \\
\text { Follow up evaluation } \\
(1 \mathrm{yr})\end{array}$ & Decrease rate & $\begin{array}{l}\text { Qualitative } \\
\text { assessment }\end{array}$ \\
\hline Spatial Orientation & $5 / 5$ & $1 / 5$ & $80 \%$ & Down \\
\hline Temporal Orientation & $5 / 5$ & $1 / 5$ & $80 \%$ & Down \\
\hline \multicolumn{5}{|l|}{ Language } \\
\hline Denomination (AAT) & $17 / 30$ & $0 / 30$ & Compromised & Down \\
\hline Phonological Fluency (Carlesimo et al.,) [16] & $20(27.9)$ & $2(9.9)$ & $64.51 \%$ & Down \\
\hline Semantic Fluency (Novelli et al.,) [17] & $31(39)$ & $4(12)$ & $69.23 \%$ & Down \\
\hline Reading & & & & Down \\
\hline Writing & & & & Down \\
\hline \multicolumn{5}{|l|}{ Intelligence } \\
\hline $\begin{array}{l}\begin{array}{l}\text { Raven's Coloured } \\
\text { (Carlesimo et al.,) }[16]\end{array} \\
\text { Progressive }\end{array}$ & $10 / 36(13.9 / 36)$ & Not valuable & & Down \\
\hline \multicolumn{5}{|l|}{ Short Memory } \\
\hline $\begin{array}{l}\text { Short Spatial Memory_Corsi's Test (Orsini et al.) } \\
\text { [18] }\end{array}$ & $5(5.5)$ & $0 / 5$ & Compromised & Down \\
\hline
\end{tabular}




\begin{tabular}{|c|c|c|c|c|}
\hline $\begin{array}{l}\text { Short Verbal Memory_ Digit Span Forward (Orsini } \\
\text { et al.,) [18] }\end{array}$ & $5(5.5)$ & $2(2.5)$ & $54.54 \%$ & Down \\
\hline \multicolumn{5}{|l|}{ Working Memory } \\
\hline Digit Span Backward (qualitative) & 2 & 0 & Compromised & Down \\
\hline \multicolumn{5}{|l|}{ Verbal Long Memory } \\
\hline $\begin{array}{l}\text { Rey's } 15 \text { word-test } \\
\text { (Carlesimo et al.,) [16] } \\
\text { Immediate Recall: } \\
\text { Delayed Recall: }\end{array}$ & $\begin{array}{l}33(39.1) \\
9(10.8)\end{array}$ & $\begin{array}{l}7(13.1) \\
0\end{array}$ & $\begin{array}{l}66.49 \% \\
\text { Compromised }\end{array}$ & $\begin{array}{l}\text { Down } \\
\text { Down }\end{array}$ \\
\hline Story Recall (Novelli et al.,.) [17] & $19.5(22)$ & 0 & Compromised & Down \\
\hline \multicolumn{5}{|l|}{ Executive Functions } \\
\hline Attentional Matrices (Spinnler and Tognoni) [19] & $15(18 / 60)$ & Not valuable & Compromised & Down \\
\hline $\begin{array}{l}\text { Trail Making Test (Giovagnoli et al.,) [20] } \\
\text { TMT-A } \\
\text { TMT-B }\end{array}$ & $\begin{array}{l}123 " \\
\text { Interrupted }\end{array}$ & $\begin{array}{l}\text { Not valuable } \\
\text { Not valuable }\end{array}$ & $\begin{array}{l}\text { Compromised } \\
\text { Compromised }\end{array}$ & $\begin{array}{l}\text { Down } \\
\text { Down }\end{array}$ \\
\hline \multicolumn{5}{|l|}{$\begin{array}{l}\text { Apraxia, Perception and Visuo-Contructional } \\
\text { Ability }\end{array}$} \\
\hline VOSP & Not valuable & Not valuable & Compromised & \\
\hline Shape Copy (Carlesimo et al.,) [16] & $0 / 12(0 / 12)$ & 0 & Compromised & Not Valuable \\
\hline Ideo-motor praxis (De renzi et al.,) [21] & $59 / 72$ & $45 / 72$ & $23.72 \%$ & Down \\
\hline
\end{tabular}

Table 1: Cognitive assessment performed at admission and one year later. The numbers in parenthesis indicate the correct score according to age and education of the patient.

\section{Discussion}

There is a growing number of reports of atypical focal cortical presentations of $\mathrm{AD}$ in patients with relatively younger onset, suggesting that diagnosis of $\mathrm{AD}$ needs to be considered even in patients who present with focal dementia without significant memory loss. Morevover, it is well established that the most frequent focal cortical presentations af AD are PCA, corticobasal syndrome (CBS), behavioural variant frontotemporal dementia (bvFTD), progressive non-fluent aphasia (PNFA) (or a mixed aphasia) and semantic dementia (SD) [7].

PCA is a focal cortical presentation of $\mathrm{AD}$, atypical for its early age at onset and because a single cognitive domain, not related to memory, is predominantly affected [3].

Establishing clinical diagnosis of PCA involves a two-step process; at first, patients should meet basic criteria based on McMonagle et al. [5], and then they can be furtherly classified into three main variants: biparietal syndrome (apraxia, visuospatial problems, agraphia, Balint's syndrome with preserved basic perceptual abilities, object recognition and reading), occipitotemporal syndrome (alexia, apperceptive agnosia and/or prosopagnosia) and visual variant (primary visual failure and impairment of basic perceptual abilities) [7].

We studied a 60-year patient with PCA and relatively short disease duration. Her clinical, cognitive and neuroradiologic findings indicate a predominantly right hemisphere dysfunction, resulting in dyspraxic difficulties, deficits in writing and impairment of visuo-spatial functions. Migliaccio et al. [8] showed that these deficits result from a selective posterior pattern of grey matter atrophy and from a damage to specific white matter pathways composing the visuo-spatial network.

CSF profile of the patient was typical for AD (characterized by alteration of ABeta42, t-tau and p-tau) [9]. The presence in our patient of the three pathological biomarkers of neurodegeneration confirm that in most in cases PCA can be considered a focal cortical variant of AD.

Previous literature studies support the hypothesis that a greater load of amyloid plaques and neurofibrillary tangles in the cerebral tissue are correlated with the earlier clinical symptoms of PCA patients and with the progressive cognitive decline $[10,11]$, Since many patients with PCA show posterior neuritic plaques and neurofibrillary tangles at autopsy, the term PCA was often used interchangeably with $\mathrm{AD}$ or "the visual variant of AD." [12]. Further studies showed the uniformity of the clinical profile of PCA, which is distinct from that of typical amnestic $\mathrm{AD}$ [5] and demonstrated that numerous conditions can mimic symptoms of PCA, including other types of progressive dementias, such as cortical basal syndrome (CBS), dementia with Lewy bodies and prion disease, in which presentation with apraxia and prominent visuospatial deficit is also common [13]

On the basis of these reports, this syndrome should be not considered exclusively a variant of $\mathrm{AD}$, but rather a distinct nosologic entity with its behavioral profile dictated by the topography of 
Citation: D'Anna L, Dolso PL, Lorenzut S, Perelli A, Zanchettin B, et al. (2014) Visuospatial Deficit and Apraxia in Posterior Cortical Atrophy (PCA): a Single Case Follow-up Study. J Neurol Disord 2: 166. doi:10.4172/2329-6895.1000166

Page 5 of 5

pathology, more than its histology, and with its own diagnostic criteria.

Ruling out $\mathrm{AD}$ may also prevent inappropriate treatment, renouncing to use someone of the many medications available for $\mathrm{AD}$, which are unnecessary for the conditions mimicking the symptoms of AD. Furthermore, whereas it is well known that a progressive amnestic syndrome in an elderly subject is highly predictive of AD pathology, in younger patients (under age 65) atypical, focal clinical syndromes which spare the long term memory may not evoke immediately the diagnosis of dementia disorder, and delay its correct treatment. For example, the visual variant of PCA can sometimes be misattributed to ocular causes, such as cataract or macular disease [11].

Our patient started therapy with transdermal rivastigmine $(4,6$ $\mathrm{mg} / 24 \mathrm{~h}$ ), and at one-year follow-up we observed a significant deterioration not only of the neuropsychological skills, but also in her daily living activities. Acetylcholinesterase inhibitors are usually reported as ineffective in the literature with, only a few cases suggesting some clinical benefits in PCA patients [14]. As far as we know, no clinical trials have been published.

In conclusion, our case report highlights the importance of making an accurate diagnosis of $\mathrm{AD}$ in clinical practice (and especially of ruling out $\mathrm{AD}$ ) in order to reduce potentially inappropriate treatments which may slow the progression of the symptoms and disability of AD but are useless for other conditions [15].

\section{References}

1. Benson DF, Davis RJ, Snyder BD (1988) Posterior cortical atrophy. Arch Neurol 45: 789-793.

2. Andrade K, Samri D, Sarazin M, de Souza LC, Cohen L, et al. (2010) Visual neglect in posterior cortical atrophy. BMC Neurol 10: 68.

3. Migliaccio R, Agosta F, Rascovsky K, Karydas A, Bonasera S, et al. (2009) Clinical syndromes associated with posterior atrophy: early age at onset AD spectrum. Neurology 73: 1571-1578.

4. Crutch SJ, Lehmann M, Schott JM, Rabinovici GD, Rossor MN, et al (2012) Posterior cortical atrophy. Lancet Neurol 11: 170-178.

5. McMonagle P, Deering F, Berliner Y, Kertesz A (2006) The cognitive profile of posterior cortical atrophy. Neurology 66: 331-338.

6. Snowden JS, Stopford CL, Julien CL, Thompson JC, Davidson Y, et al (2007) Cognitive phenotypes in Alzheimer's disease and genetic risk Cortex 43: 835-845.
7. Alladi S, Xuereb J, Bak T, Nestor P, Knibb J, et al. (2007) Focal cortical presentations of Alzheimer's disease. Brain 130: 2636-2645.

8. Migliaccio R, Agosta F, Toba MN, Samri D, Corlier F, et al. (2012) Brain networks in posterior cortical atrophy: a single case tractography study and literature review. Cortex 48: 1298-1309.

9. Seguin J, Formaglio M, Perret-Liaudet A, Quadrio I, Tholance Y, et al. (2011) CSF biomarkers in posterior cortical atrophy. Neurology 76: 1782-1788.

10. von Gunten A, Bouras C, Kövari E, Giannakopoulos P, Hof PR (2006) Neural substrates of cognitive and behavioral deficits in atypical Alzheimer's disease. Brain Res Rev 51: 176-211.

11. Renner JA, Burns JM, Hou CE, McKeel DW Jr, Storandt M, et al. (2004) Progressive posterior cortical dysfunction: a clinicopathologic series. Neurology 63: 1175-1180.

12. Levine DN, Lee JM, Fisher CM (1993) The visual variant of Alzheimer's disease: a clinicopathologic case study. Neurology 43: 305-313.

13. Bak TH, Rogers TT, Crawford LM, Hearn VC, Mathuranath PS, et al. (2005) Cognitive bedside assessment in atypical parkinsonian syndromes. J Neurol Neurosurg Psychiatry 76: 420-422.

14. Kim E, Lee Y, Lee J, Han SH (2005) A case with cholinesterase inhibitor responsive asymmetric posterior cortical atrophy. Clin Neurol Neurosurg 108: 97-101.

15. Gaugler JE, Ascher-Svanum H, Roth DL, Fafowora T, Siderowf A, et al. (2013) Characteristics of patients misdiagnosed with Alzheimer's disease and their medication use: an analysis of the NACC-UDS database. BMC Geriatr 13: 137.

16. Carlesimo CA, Caltagirone C, Gainotti G, Nocentini U (1995) Batteria e affidabilità diagnostica nell'identificazione di pazienti affetti da sindrome demenziale. Archivio di Psicologia, Neurologia e Psichiatria. 56: 471-88.

17. Novelli G, Papagno C, Capitani E, Laicona M, Vallar G, Cappa SF (1986) Tre test clinic di ricerca e produzione lessicale. Taratura su soggetti normali. Archivio di Psicologia Neurologia e Psichiatria 4: 477-506.

18. Orsini A, Grossi D, Capitani E, Laiacona M, Papagno C, et al. (1987) Verbal and spatial immediate memory span: normative data from 1355 adults and 1112 children. Ital J Neurol Sci 8: 539-548.

19. Spinnler H, Tognoni G (1987) Taratura e standardizzazione italiana di test neuorpsicologici. The Italian Journal of Neurological Sciences Suppl. 8.

20. Giovagnoli AR, Del Pesce M, Mascheroni S, Simoncelli M, Laiacona M, et al. (1996) Trail making test: normative values from 287 normal adult controls. Ital J Neurol Sci 17: 305-309.

21. De Renzi E, Motti F, Nichelli P (1980) Imitating gestures. A quantitative approach to ideomotor apraxia. Arch Neurol 37: 6-10. 